
\section{Universidade Federal de São Paulo, Brasil rafarui@hotmail.com Recibido: 11.06 .20 Aceptado: 03.11.20}

Rafael Ruiz*

\title{
Argumentos retóricos y elementos de prueba en procesos criminales de la Real Audiencia de Lima a finales del siglo XVIII
}

\author{
Rhetorical arguments and evidence elements in criminal \\ cases in the "Real Audiencia de Lima" at the end of the 18th \\ century
}

Resumen: La finalidad de este trabajo es la de analizar los argumentos retóricos presentados como elementos de prueba por las partes litigantes en procesos criminales juzgados en la Real Audiencia de Lima, a finales del siglo XVIII. Intentaré mostrar cómo una de las cuestiones más importantes, en procesos de "difícil probación", eran las presunciones legales y las conjeturas, y cómo esos medios de prueba no eran tan solo una ficción jurídica, sino, también y, principalmente, una cuestión de argumentación retórica, filosófica, moral y teológica. La hipótesis que sustentaeste trabajo parte delaidea de que las presunciones legales al fortalecer, tanto lo que se piensa habitualmente como lo que ocurre generalmente, terminan confirmándolos, negándolos o modificándolos, a partir de los procesos históricos y sociales. A partir de los casos analizados, intentaré mostrar la lógica retórica y argumentativa y los cambios semánticos ocurridos con relación a la "patria potestad". La fuente documental se encuentra en el Archivo General de la Nación, en Lima, sección Real Audiencia, Causas Criminales. Serán utilizados dos procesos por crimen de rapto y estupro, uno antes y otro después de la publicación de la Pragmática Sanción, con una diferencia, entre ambos, de 48 años.

Palabras clave: retórica jurídica; presunción; probabilismo; patrio poder; Pragmática Sanción.
Abstract: This work aims to analyze the rhetorical arguments presented as evidence by the litigating parties in criminal proceedings tried in the Real Audiencia de Lima, at the end of the eighteenth century. I will try to show how one of the most significant issues in processes "hard to prove" were legal presumptions and conjectures. Likewise, besides legal fiction, how these means of proof were mainly a case of rhetorical, philosophical, moral, and theological argumentation. The hypothesis supporting this work rests on the idea that legal presumptions, by strengthening what is usually thought and generally occurs, end up confirming, denying, or modifying legal concepts based on historical and social processes. I will try to show the rhetorical and argumentative logic and the semantic changes regarding "parental authority" from the cases analyzed. The documentary source is found in the Archivo General de la Nación, in Lima, section Real Audiencia, Causas Criminales. I will use two kidnapping and statutory rape processes that occurred with a difference of 48 years between them-one before the publication of the Pragmática Sanción and the other one after.

Keywords: legal rhetoric; presumption; probabilism; parental authority; Pragmática Sanción.

\footnotetext{
* El autor agradece a la FAPESP por la beca concedida para el desarrollo de esta investigación.
} 


\section{Rafael Ruiz}

El término "retórica", desde hace ya bastante tiempo, como indicaba Perelman a finales de los años setenta del siglo pasado, lleva a pensar en algo que "degeneró en el siglo XVI al quedar reducida a un estudio de figuras de estilo" (Perelman, 1979, p. 139) y, creo que, sin exageración, en los tiempos que corren, es entendida todavía tan solo como algo cercano al campo de las letras o de las figuras del discurso y de la elocuencia.

Por su parte, Olivier Reboul, en su libro sobre retórica, explicaba este hecho diciendo que fue a partir del Renacimiento cuando se produjo el proceso de su decadencia. Para Reboul, y muchos otros autores, "fue el humanista Pedro Ramus (Pierre de la Ramée, 1515-1572) quien separó "la Dialéctica, arte de la argumentación racional, de la Retórica, reduciéndola al estudio de los medios de expresión ornados y agradables, o sea, reduciéndola a la elocuencia" (Reboul, 2004, p. 79).

No será en este sentido, de un arte del bien hablar y de la elocuencia elegante por medio de figuras del lenguaje, que lo utilizaré en este artículo. Lo haré desde el punto de vista de la "nueva retórica", destacada por los trabajos de Chaim Perelman, que siempre defendió la fuerza de la argumentación retórica como forma de llegar a la persuasión y a la convicción.

De acuerdo con Perelman, al lidiar con procesos judiciales, habría que tener en cuenta que "la argumentación no contempla exclusivamente la adhesión a una tesis porque sea verdadera. Podemos preferir una tesis a otra porque nos parezca más equitativa, más oportuna, más actual, más razonable o mejor adaptada a la situación" (Perelman, 1979, p. 153).

Y, aún de acuerdo con Perelman, "la búsqueda de soluciones concretas obliga con frecuencia a reinterpretar los principios, a contraponer el espíritu a la letra de la ley o lo que es lo mismo, el punto de vista práctico, esto es, el que toma en consideración las consecuencias que resultan de la aplicación de una regla, frente al punto de vista formalista, que es el de la aplicación literal del texto. Adoptando uno u otro punto de vista, interpretaremos los términos de la ley de una manera más rígida o más flexible" (Perelman, 1979, p. 160).

Me parece que las afirmaciones de Perelman ayudan a entender mejor la naturaleza peculiar de los elementos de prueba que pretendo discutir en este trabajo. Las presunciones, las suposiciones, los indicios o las conjeturas se desarrollan más en el terreno de lo dudoso que de lo verdadero, se apoyan más en lo verosímil que en la verdad, y su fuerza muchas veces se encuentra, como también afirma Rosoni, en el sentido común o en lo que habitualmente sucede, de tal manera que, si un argumento no llegara a ser verosímil, no podría ser presumido (Rosoni, 1995, p. 103).

En ese sentido, y volviendo a Perelman, me parece que analizar los procesos a partir de ese punto de vista podrá dar más luz sobre los fundamentos y las hipótesis en que se apoyaban dichas suposiciones, ya que, el hecho de plantear una presunción como argumento capaz de formar la convicción del juez tendría que apoyarse en una interpretación más flexible de la ley y de los hechos.

La fuerza del argumento más que en la letra de la ley, podía ser encontrada en lo que solía suceder y probablemente habría sucedido de aquella manera. 0 sea, probablemente podría haber sucedido, pero quizás no. Esa incerteza y esa probabilidad, más que una forma de percepción o de cognición de la realidad, eran el telón de fondo en que se desarrollaba la vida (Caro, 1978). $Y$ fue precisamente en esa forma incierta y tan solo probable de entender la vida que se desarrolló el probabilismo, dentro de la teología moral católica'.

Mi hipótesis de trabajo sostiene que las presunciones legales, precisamente por apoyarse en lo que se piensa o en lo que ocurre habitualmente, y analizando esas 
presunciones en un plazo de tiempo relativamente largo, pueden dar una luz más clara sobre el sentido y el vigor de una determinada categoría jurídica, sobre su fuerza coactiva, sus cambios semánticos o sus modificaciones y adaptaciones a las vicisitudes históricas y sociales.

Al escoger la categoría de "patria potestad" lo hice pensando en que, de alguna manera y de acuerdo con una tendencia historiográfica dominante, es una de aquellas figuras que manifiestan de forma más clara el tenor autoritario y coactivo de lo que se ha dado en llamar "patriarcalismo del Antiguo Régimen".

Y, en ese sentido, el objetivo de este artículo es intentar mostrar, a partir de los casos analizados, el carácter histórico jurídico del concepto de "patria potestad" y hacer ver que ese mismo concepto demanda una reflexión en torno a su significado, dado que, debido a las mudanzas del significante con el correr del tiempo, se hace necesario matizar su contenido según el escenario temporal y espacial.

Con eso, creo que sigo una corriente de investigadores que, principalmente en el campo de la historia, también están cuestionando categorías históricas y jurídicas a las que estábamos acostumbrados desde hace tiempo².

Los procesos escogidos obedecen al hecho de que tratan sobre la "patria potestad" antes y después de la Pragmática Sanción de Carlos III, de 1776 (1778 para la América española), con un intervalo de tiempo próximo a los cincuenta años. Como se sabe, la Pragmática pretendía reafirmar la "patria potestad" sobre la voluntad individual de los hijos, considerando que no se podía permitir que hubiera casamientos desiguales por motivos de raza, etnia o estado y posición económica.
Mi trabajo se centrará en mostrar, por medio de los argumentos utilizados por la defensa y por la acusación, en qué medida y hasta qué punto un tipo o concepto jurídico puede cambiar de sentido y de significado a lo largo del proceso histórico.

En un artículo relativamente reciente, el historiador Fuentes-Barragán (2016, pp. 53-84) resume con detalle el estado actual de la cuestión en torno a la Pragmática Sanción de Carlos III y a los juicios de disenso. Su resumen abarca trabajos clásicos y señeros como el de Nelly R. Porro (1978), de finales de la década del setenta, bien como, ya más recientes, el de Noemí del Carmen Bistué y Cecilia Marigliano (1992, pp. 75-101), para el área de Mendoza, el de Mónica Ghirardi (2004) para Córdoba, o el de Viviana Kluger (1997, p. 365-390), para el Virreinato del Río de la Plata, y los trabajos de varios otros historiadores que estudiaron la Pragmática y los disensos.

Mi intento aquí no es el de tratar propiamente de la Pragmática Sanción sino el de analizar las formas argumentativas utilizadas por las presunciones y suposiciones legales como formas de probar las permanencias y los cambios semánticos de la "patria potestad" en el Virreinato del Perú. Remito a esos artículos y autores para un estudio más detallado sobre la Pragmática Sanción y sus aplicaciones y modificaciones a lo largo del tiempo, ya que, como el mismo FuentesBarragán indicaba en su trabajo, se pueden verificar hasta diez ediciones de la Pragmática, siendo las más popular la de 1803 (Fuentes-Barragán, 2016, p. 55).

\footnotetext{
${ }^{1}$ La Teología moral desarrolló a lo largo del siglo XVII y buena parte del XVIII una enorme cantidad de libros y tratados sobre la "opinión probable" y la conciencia y, de manera general, en casi todos había por lo menos un capítulo o sección o apartado dedicado a los casos y situaciones en que los jueces podrían decidir "de acuerdo con su conciencia" y "sin miedo de perder su alma". Para un estudio más detallado se pueden ver Maryks (2008); Tutino (2014) y Tutino (2018).

${ }^{2}$ Algunos estudios más recientes en Bustamante (2019), quien se refiere a la necesidad de matizar con relación al trabajo femenino (pp. 86 y ss.). En relación a la categoría "casta" y "sociedad de castas" es interesante el artículo de Giraudo (2018).
} 


\section{Algunas reflexiones necesarias sobre los medios de prueba}

Antes de abordar el tema de este artículo, me parece aún necesario hacer una digresión filosófica y metodológica para poder encuadrarlo mejor.

De acuerdo con algunos historiadores del derecho, los siglos XVI y XVII significaron el momento histórico en que se desarrolló de forma más consistente la "construcción del sistema probatorio" (Rosoni, 1995, p. 5). Se trató de un largo proceso, de poco más de un siglo y medio, en que, principalmente a partir del descubrimiento de América y de la revolución del método, de la experiencia y de la crítica en el terreno epistemológico, en gran medida por medio de Bacon y Descartes, lo que se tenía como verdades asentadas durante la época medieval sufrió un proceso de erosión y de cambios a partir de cuestiones como la duda, la certeza e incerteza.

Fue precisamente durante ese mismo período histórico que, por medio de la Compañía de Jesús, se desarrolló el sistema moral conocido posteriormente como "probabilismo" que, por la relación tan estrecha que había entre lo moral y lo jurídico durante esa temprana modernidad, fue decisivo para el perfeccionamiento y desarrollo de la teoría sobre los medios de prueba.

Poco a poco, la conexión entre lógica, retórica y el papel de lo probable en el proceso judicial fue quedando más claro, ya que la misma naturaleza de todo proceso judicial se apoyaba principalmente en aquello que fue siendo llamado "prueba indiciaria"3 , o sea, aquella que se nutría y fundamentaba en indicios, presunciones, conjeturas y suposiciones que no llegaban completamente a la verdad, pero sí se aproximaban lo suficientemente a ella. Eran opiniones más o menos ajustadas a la verdad, de acuerdo con el tenor de los indicios y presunciones, que configuraban de esa manera una "certeza probable" y no una "verdad plena" (Rosoni, 1995, p. 5).

La teoría de la prueba se fue elaborando con un particular tipo de retórica que, a partir de un modelo cognitivo fundamentado en la argumentación, permitía que se llegase a una certeza suficiente de que los hechos narrados y discutidos en juicio posiblemente habrían sucedido de aquella forma 4 . Como afirma Rosoni, esa teoría partía de una premisa o presupuesto que sirvió de fundamento para el desarrollo de la teoría de la prueba: una vez que se dejó de lado la tentativa de llegar a la verdad "plena", se podía aceptar que el juez sentenciara, sin miedo de "perder su alma", apoyando sus sentencias en la verdad probable, o sea, en aquella que se podía deducir de los argumentos retóricos que eran presentados por las partes en el proceso (Rosoni, 1995, p. 10).

Aristóteles, al explicar las relaciones entre conocimiento, lenguaje y ser ${ }^{5}$, estableció una distinción que tendría una enorme transcendencia a lo largo de los siglos, de tal forma que hasta hoy podemos afirmar que pueden ser encontrados en el filósofo griego los fundamentos sobre los "medios de prueba", o sea, sobre aquellos medios que el hombre podría usar para probar una cosa o una afirmación.

\footnotetext{
${ }^{3}$ Se hace inevitable recordar aquí el "paradigma indiciario" de Carlo Ginzburg (1989) y, concretamente, aquella distinción que hace entre una "alta intuición" y una "baja intuición" al referirse al término árabe firasa, que, como él mismo decía, se refería al "órgano del saber indiciario" (p. 179).

${ }^{4}$ Hay un camino bastante largo, desde Platón y Aristóteles hasta el siglo XVIII, pasando por toda la Edad Media y por la influencia del derecho canónico, en que se fue desarrollando la teoría de la prueba como argumentum. Sobre ese tema, se puede ver Giuliani (1964). Sobre la cuestión de la "verdad de los hechos" y la "verdad de la prueba", puede ser interesante confrontar Taruffo (2014).

${ }^{5}$ Para un estudio más detallado de esas relaciones, véase Chilló (2015).
} 
En primer lugar, al hablar sobre las formas de conocimiento, dijo que había un conocimiento que era el de las cosas necesarias y otro el de las contingentes, que podrían ser de una o de otra manera y no de una única y necesaria forma. Con relación a las primeras se tendría ciencia y con relación a las segundas, retórica, porque se estaba en el terreno de la opinión. Las verdades de la ciencia serían probadas por la demostración, mientras que las de la retórica sería por medio de la argumentación.

Y al tratar específicamente sobre la retórica, además de explicar que sería "la facultad de teorizar lo que es adecuado en cada caso para convencer" (Aristóteles, Retórica, Lib. I, Cap. 2.1, 1355b, 25), también clasificó los medios de pruebas, de manera que habría pruebas naturales y pruebas artificiales (Aristóteles, Retórica, Lib. I, Cap. 2.2, 1355b, 35, y Cap. 15.1, 1375a-1377b).

Pero lo que me interesa en este artículo es la siguiente pregunta: ¿por qué son necesarias las pruebas?

Porque en la mayor parte de los casos de la vida, continúa diciendo Aristóteles, y principalmente en las cuestiones morales, políticas o jurídicas, en que las cosas no son necesariamente de una única forma, sino que dependen de los diferentes puntos de vista de los implicados en cada cuestión, el nivel de certeza a que se puede llegar con relación a la verdad nunca es completo ni absoluto. Y era por eso que Aristóteles se refería a otras categorías próximas a la verdad: lo verosímil y lo probable. Y será a partir de esas categorías que se irá elaborando lo que se podría llamar teoría de la prueba indiciaria, o sea, ¿cómo y por qué medios se podría probar algo en un proceso judicial, a partir de indicios, señales, argumentos y conjeturas?

Giacomo Menochio, renombrado jurista del siglo $\mathrm{XVI}$, en su libro sobre las presunciones, explicaba que la presunción era aquella que nacía de cosas $u$ opiniones probables $^{6}$ (Menochio, 1575, lib.l, q. 7, n. 2) y, al profundizar sobre la cuestión de si aquello que fuese probado sería "verdaderamente la verdad", afirmaba que el medio que la presunción usaba para probar era un argumento verosímil, formado a partir o bien de cosas probables o bien de aquello que comúnmente sucedía ${ }^{7}$ (Menochio, 1575, lib.l, q. 7, n. 36).

Podríamos decir, por lo tanto, que, de manera general, la definición más común de presunción estaba relacionada con la idea de una conjetura probable sobre alguna cosa incierta, siendo una forma particular de raciocinio, por medio del cual, de un hecho supuesto como conocido se llegaba a un hecho desconocido y que, desde entonces, se tenía como probado, hasta que no se probase lo contrario (Rosoni, 1995, pp. 100-102).

Todo este entramado retórico que con los griegos estuvo intrínsecamente relacionado con la filosofía, con los romanos, principalmente con Cicerón y Quintiliano, pasó a hacer parte del mundo jurídico (Villey, 1979). Para Cicerón, "rueba es lo que persuade al juez, ante una cosa dudosa, por medio de argumentos" (Giuliani,1964, p. 358). Me parece que es claro cómo Cicerón introduce la Retórica aristotélica en una llave jurídica y procesal. Ante la falta de certidumbre (ante la duda) se hace necesario probar. Pero, ¿con qué finalidad? Para persuadir al juez. Y ¿cómo? Probando lo que se afirma por medio de argumentos. No de cualquier manera, ni por cualesquiera medios, sino tan solo por aquellos que sean relevantes para el caso concreto.

En términos procesales -y para los efectos que interesan en este artículo- la dinámica procesal con sus fases, su iter, y sus normas sobre lo que podría ser considerado como medio de prueba y cómo y por quién debería ser probado, tenía como finalidad que las partes, acusación y defensa, por medio de la presentación de sus pruebas y de sus alegaciones y argumentos presentados en juicio llevasen al juez a través de un camino (procedereprocessus) de la ignorancia al conocimiento que, en la mayor parte de los casos, era un conocimiento incierto o, con otras palabras, era una certeza moral.

\footnotetext{
${ }^{6}$ Pressumptio illa est quae interdum oritur a probabilibus.

${ }^{7}$ Fit enim verisimile argumentum ex rebus probabilibus, et quae plerumque ita fiunt.
} 


\section{Rafael Ruiz}

En ese sentido, uno de los mayores juristas medievales, Bartolo, consideraba cinco etapas que el juez tendría que recorrer antes de llegar a la certeza suficiente para formar su propia convicción: 1) "nescientia" (ignorancia), cuando el juez carecía de cualquier base o fundamento para formar cualquier tipo de juicio; 2) "dubitatio" (duda), cuando se encontraba en la incertidumbre frente a los argumentos presentados; 3) "suspicatio" (inclinación, sospecha), cuando tenía algunos leves indicios para formar su juicio, pero todavía continuaba en la duda; 4) "opinio" (opinión), cuando el juez superaba la duda razonable y formaba una opinión y 5) "fides" (confianza), cuando, finalmente, transformaba su opinión en una convicción firme, adhiriéndose a los argumentos de una de las dos partes y, por lo tanto, estando en condiciones de proferir su sentencia (Rosoni, 1995, pp. 236-237).

A lo largo de todo este proceso histórico, la tradición procesal de ambos derechos, el civil y el canónico, fue estableciendo los varios niveles o grados de "fuerza probatoria"8. De esa manera, si la presunción era bastante fuerte se asimilaba a la prueba; si no era tan fuerte, se asimilaba a la verosimilitud; y cuando era poco más que dudosa o incierta, se asimilaba a la conjetura (Rosoni, 1995, p. 218). Y cuando se trataba de algún tipo de raciocinio construido a partir de los usos y costumbres, o sea, de aquello que solía acontecer, o de la propia experiencia humana compartida, entonces adquiría el estatus jurídico de presunción simple, que se aceptaba siempre y cuando no fuese probado lo contrario (Rosoni, 1995, p. 221). De esa manera, la presunción, como categoría retórica y jurídica, se encontraba profundamente relacionada con lo probable, como categoría teológica y moral. Todas esas eran formas indiciarias de probar los hechos.
Lo que quisiera destacar al final de este largo paréntesis son dos cuestiones que me parecen poco estudiadas por la historiografía y que comparto con algunos historiadores ${ }^{9}$. La primera es la afirmación de que la sentencia del juez no se fundamentaba en "la verdad de los hechos", que incluso, por la misma naturaleza del proceso cognitivo, era algo imposible, sino en su reconstrucción mental, imaginativa y subjetiva, que cada juez hacía sobre la verosimilitud de las narrativas y argumentos que las partes presentaban sobre los hechos (Taruffo, 2005 y 2014). Y la segunda es que para formar ese juicio y llegar a una convicción no podría prescindir de una larga gradación de posibilidades de eventos probables (Rosoni, 1995, p. 222) y, en ese sentido, tendría que llevar en cuenta todo lo que, hasta aquel momento, la teología moral católica había desarrollado y escrito sobre el nuevo y moderno sistema moral conocido con el nombre de probabilismo ${ }^{10}$.

La prueba por presunción nacía de un tipo de raciocinio argumentativo que partía de afirmaciones probables o de hipótesis o de ejemplos o, para usar el término genérico, de indicios (Rosoni, 1995, p. 224). El grado de certeza que esos argumentos retóricos ofrecían al juez era, ni más ni menos, que una certeza moral, pero, como afirmaba casi unánimemente la mayoría de los teólogos, era una certeza suficiente para sentenciar en conciencia, sin miedo de perder la propia alma.

\footnotetext{
${ }^{8}$ Para todo este tema, además de la obra de Rosoni (1995), puede ser útil mi trabajo Pruebas sobre los medios de prueba: Ruiz (2017 b). ${ }^{9}$ Ortego (2013; 2012 y 2009); Turrini (1996; 1994); Padoa-Schioppa (2001).

${ }_{10}$ Además de las obras ya citadas de Maryks y Tutino, añado algunos trabajos, teniendo en cuenta que la bibliografía es muy extensa: Macera (1963); Martel (2007); Muñoz (2003); Mayer (2015); Schüssler (2005) y Palumbo (2013).
} 


\section{Certeza, incerteza y probabilismo}

Como dije, he tenido que hacer una digresión que me pareció necesaria (y que espero que no haya sido demasiado larga) para poder enmarcar mejor el análisis que pretendo hacer de los procesos criminales del siglo XVIII a partir de las presunciones y suposiciones como medios de prueba, teniendo en cuenta tanto una perspectiva retórica como el sistema moral probabilista.

El probabilismo significó un cambio de paradigma en la teología moral católica. Se pasó de una perspectiva rigorista, objetiva y categórica, propia del mundo medieval, para otra perspectiva ya moderna, flexible, subjetiva e incierta (Maryks, 2008, p. 117).

Esa perspectiva moral, precisamente por las intrínsecas relaciones que lo moral y lo jurídico tenían durante esa época, afectó no solo el campo de la moralidad, sino -y es por eso que toda esta introducción se hizo necesaria - el campo de lo jurídico. Un juez prudente no estaba obligado a sentenciar de una única manera que le pareciera la más justa. Delante de varias opiniones de diferentes juristas y teólogos sobre las leyes y sus interpretaciones, el juez podría escoger aquella que le pareciera más o menos probable para formar su convicción. Y ya que no se podía contar con la autoridad de la "verdad plena", el fundamento de la autoridad que le permitiría escoger una u otra opinión era, normalmente, la fuerza de los argumentos presentados.

Fue a esta altura que la retórica, propia de los filósofos y juristas de la época clásica, se unió con el probabilismo de la teología moral católica. En el campo judicial y procesal, se fue construyendo "una teoría de la certeza moral ligada al principio de la probabilidad” (Rosoni, 1995, p. 26), legitimando de esa manera la relevancia y eficacia de probar algo no por evidencia, sino por indicios, que garantizarían la certeza probable (Rosoni, 1995, p. 26), suficiente para sentenciar en conciencia.

En relación con el desarrollo de la "materia probatoria" en términos procesales, son relativamente recientes los estudios que empiezan a dar importancia a la Escuela de Salamanca. De manera bastante simplificada, y para efectos didácticos, teniendo en cuenta que una matización mayor nos desviaría - y mucho- del tema, me gustaría hacer una división inicial. Podríamos hablar de que hubo dos grandes momentos en el transcurso histórico de la prueba: antes y después de la Segunda Escolástica.

Cuando se hace referencia a una "Segunda Escolástica"11, normalmente se hace referencia al hecho de que el pensamiento de Tomás de Aquino se fue reformulando en la Escuela de Salamanca por medio de Francisco de Vitoria y de los teólogos que fueron sus seguidores y discípulos y que, al serle ofrecida una nueva situación social, económica, religiosa, moral y política, buscaron reelaborar el pensamiento tomista dejando de lado una moral teórica y rígida en favor de una moral práctica, casuística y flexible, en la que se desarrollaron en poquísimo tiempo las diferentes corrientes morales conocidas como probabilismo ${ }^{12}$.

Lo que quisiera destacar aquí es el hecho de que en esa Segunda Escolástica hubo un punto de inflexión con relación al tema de la verdad y de la certeza. La "verdad" fue siendo relegada al campo de la fe y del dogma, mientras que la "certeza" se ocuparía de los "actos humanos", porque, conforme Aristóteles y de acuerdo con Tomás de Aquino (Summa Theologiae, II-Ilae, q. 70

\footnotetext{
${ }^{11}$ Algunos trabajos sobre este tema: Prodi (2005); Grossi (1973); Todescan, (1973) y Belda (2000).

12 Sobre este asunto, un artículo que explica bien las distinciones puede ser el de Llamosas (2011). Puede ser también interesante, Vidal (1986).
} 
a. 2 c. $)^{13}$, sobre los juicios humanos no cabía esperar una "certeza demostrativa", siendo suficiente una "certeza probable". De esa manera, se pasó a entender que, en el proceso civil o criminal, bastaba que el juez actuase y sentenciase no de acuerdo con la "verdad de los hechos" (que probablemente nunca sería alcanzada), sino con la "certeza probable" a la que se llegaría, a través de las pruebas, de los indicios, de las conjeturas y suposiciones, de tal forma que pudiese formar una convicción firme excluyendo cualquier duda razonable (Vitellio, 2007, p. 22).
De todo esto se deduce la importancia de conocer y profundizar en las argumentaciones de abogados y fiscales porque, si fueren verosímiles, probables, posibles o razonables, podrían fundamentar la convicción y la sentencia de los jueces. Y eso significaría que la aplicación de la justicia en la América española permitiría una flexibilidad y una relativización con relación a las leyes reales.

\section{Matrimonio y patria potestad: presunciones y suposiciones}

A finales del XVIII, la ciudad de Lima podría contar con una población de aproximadamente 50.000 o 60.000 habitantes (Bustamante, 2019, p. 122), de los cuales, el $38 \%$ era formado por españoles, el 18\%, por negros, el $9 \%$ estaba constituido por mestizos, el $8 \%$, por indios, y las castas constituían el 27\% restante (Bustamante, 2019, p. $122)^{14}$. Para el afán reformador de los Borbones a finales del XVIII, esa composición tan heterogénea y marcadamente "plebea"15 se configuraba como un lugar de desórdenes y disturbios contra el bien y la tranquilidad de la Res publica.

Las reformas borbónicas no alcanzaron tan solo las estructuras institucionales del Virreinato, como se ha destacado en los estudios sobre el tema, sino también modificaron la vida cotidiana y doméstica. La Pragmática Sanción de Carlos III, publicada el 23 de marzo de 1776 en España, y el 7 de abril de 1778 en los territorios americanos, "para evitar el abuso de los casamientos desiguales" (Konetzke, III, 1, 1962, pp. 406413), pretendía proteger el orden social, por medio de la eliminación o, por lo menos, de la disminución de los matrimonios entre personas de razas y castas diferentes.

En pocas palabras, la Corona quería reforzar la "patria potestad", prohibiendo que los hijos e hijas menores de 25 años se pudieran casar libremente y de acuerdo con su libre albedrío, reforzando así el poder paterno para conceder o negar su permiso para la unión matrimonial (Marre, 1997, pp. 217-249). La finalidad explícita de la ley era que los padres conservasen su autoridad, emergente de la patria potestad, en la "intervención y consentimiento de los matrimonios de sus hijos" (Konetzke, III, 1, 1962, p. 409) ${ }^{16}$.

Como resume adecuadamente Bustamante en su obra ya citada, para algunos historiadores (Socolow, 1991, pp. 229-270; Gutiérrez, 1993, p. 376), la Pragmática podría

\footnotetext{
${ }^{13}$ Tomás de Aquino en la Summa Theologiae, II-Ilae, q. 70 a. 2 c.: "Según el Filósofo, en I Ethic., no se debe exigir la misma certidumbre en todas las materias. Acerca de los actos humanos, sobre los que versan los juicios y son exigidos los testimonios, no puede tenerse una certeza demostrativa, puesto que dichos actos versan sobre cosas contingentes y variables, y, por tanto, es bastante la certeza probable que alcance a la verdad en la mayoría de los casos, aunque en muy pocos se separe de ella. Ahora bien: es probable que la declaración de muchos testigos contenga más la verdad que el dicho de uno solo" (las cursivas son mías).

${ }^{14}$ Con relación al concepto de "casta" y de "sociedad de castas" véase el artículo de Stolcke (2009).

${ }^{15}$ Sobre el concepto de "plebe" y sus implicaciones en la política reformista borbónica, véase Bustamante (2019) pp. 122 y siguientes.

16 "[C]onservar a los padres de familia la debida y arreglada autoridad que, por todos derechos, les corresponden en la intervención y consentimiento de los matrimonios de sus hijos".
} 
ser vista desde el punto de vista del enfrentamiento que los Borbones estaban manteniendo contra la Iglesia católica y los tribunales eclesiásticos. La tendencia por parte de estos tribunales era la de permitir y favorecer, siempre que fuera posible, el libre albedrío de los novios, aunque eso tuviera como resultado, más o menos deseado, el mestizaje. De cualquier manera, la posición de la Iglesia no era rigorista, sino flexible y probabilista, adoptando en cada caso y en cada unión la decisión que le pareciera más prudente ${ }^{17}$.

Para los planes reformistas de los Borbones, parecía evidente que esa práctica contribuía para aumentar y diseminar "los desórdenes que se introducen con el transcurso del tiempo" porque, como podía comprobarse con facilidad la unión entre personas de diferentes castas, razas y etnias era tan frecuente que resultaba en la "turbación del buen orden del Estado y continuadas discordias y perjuicios de las familias" (Konetzke, III, 1, 1962, p.406).

Otros historiadores, siguiendo aún a Bustamante, tienden a considerar que se trataba más de reforzar el patriarcado y la autoridad paterna que debía imponerse en aquellos casos en que hubiese una desigualdad muy grande entre los futuros esposos (Lavrin, 1991). Y, para otros, los Borbones intentaban introducir por la vía de la normatividad legislativa cambios sociales significativos en el campo del matrimonio, que era una jurisdicción mixta con la Iglesia y, consecuentemente, disminuir la influencia de la Iglesia en esas cuestiones (Seed, 1991). Se trataría, en ese sentido, de aumentar su política regalista, siguiendo las tendencias ilustradas del XVIII (Bistué y Marigliano, 1997 p. 80).

Y para algunos, la tensión entre la Iglesia y el Estado estaba puesta en el reconocimiento e introducción, por parte de la Iglesia, no solo de la libertad de las conciencias y de las voluntades de los novios, sino $-y$ de cierta forma, eso era ya un fenómeno nuevo y revolucionariode la idea del "amor" como motivo y fundamento de la elección de los cónyuges. De acuerdo con los términos de la Pragmática, las "ciegas pasiones" impedían que los jóvenes viesen cualquier cosa un poco más allá de sus propios deseos, olvidándose de los intereses paternos y familiares (Gutiérrez, 1993).

De cualquier forma, me parece que hay un cierto consenso en torno a la idea de que se trataba de reforzar, por parte del Estado, la autoridad paterna en los casos en que el statu quo social, familiar y económico $-\mathrm{y}$, en consecuencia, político - estuviese en riesgo de perderse o de no ser efectivo, sin dejar, a la vez, de perder el control sobre esas relaciones paterno-filiales.

En este sentido, Fuentes-Barragán encuentra una cierta tensión paradójica entre ese refuerzo de la autoridad paterna, que no permite que los hijos sean libres a la hora de contraer matrimonio y, a la vez, permitiendo los juicios de disenso, lo que mermaría los excesivos y exagerados controles por parte de los padres (Fuentes-Barragán, 2016, pp. 53-84).

Es precisamente en este punto que quiero colocar mi hipótesis de trabajo y de análisis. Me parece que el concepto de "patria potestad", como una manifestación del poder patriarcal del Antiguo Régimen, sufriría un proceso de cambio, a lo largo del tiempo y, sin duda en la segunda mitad del siglo XVIII, ya es una categoría sin vigencia social dominante.

Quiero decir con esto que, en ese período entre, aproximadamente 1750-1820, no se verificaban más las condiciones, ni las formas y mucho menos la fuerza y coacción que se entienden como "propias" o "características" de la patria potestad ${ }^{18}$. No quiero decir con eso que no existiera o que no se reconociese la "patria potestad", quiero decir que me parece que no se puede utilizar esa categoría en el mismo sentido y de forma homogénea para todo el período del así llamado Antiguo Régimen, ni para toda y cualquier localidad de la América española. Se hace necesario matizar y detallar.

\footnotetext{
${ }_{17}$ Sobre este tema, pido permiso para remitir a mi artículo Ruiz (2017 a).

${ }^{18}$ Sobre la poca y escasa eficacia de la Pragmática, se puede ver Bustamante (2019), las páginas 125 y siguientes.
} 


\section{Rafael Ruiz}

Procuraré comprobar mi hipótesis a partir del análisis de dos procesos criminales en que se recurre e invoca a la "patria potestad" de manera "sui generis". El primero transcurrió antes y el segundo después de 1778, con una diferencia de 48 años entre ellos. Entiendo y acepto la posible crítica de que son muy pocos procesos para que se pueda hacer una afirmación general con relativa certeza, pero, como dije, por ahora, querría establecer este artículo como una hipótesis de trabajo.

\section{Los procesos analizados}

El primer caso es un proceso criminal juzgado en 1752 por la Real Audiencia de Lima, 26 años antes de la publicación de la Pragmática Sanción. La causa fue iniciada contra un pardo libre por el padre de la víctima, hija doncella de veinte años, bajo la acusación de rapto, estupro, adulterio e invasión de morada (A.G.N., 1752, L. 15, C. 161).

Lo que más llama la atención en la fase sumaria (con la que se verificaba si había indicios o pruebas que permitiesen empezar el proceso) son los argumentos presentados por el padre. Para la acusación, el problema no estaba propiamente en el estupro, sino en el hecho de que había una desigualdad insuperable entre su hija, "española por los cuatro costados", y el supuesto agresor, un mulato pobre, de una "total indigencia (...) descalzo de pie y pierna" (A.G.N., 1752, f. 7v.). Como se sabe, ese era uno de los principales argumentos suficientes para impedir el matrimonio, pero hay que tener en cuenta que la Pragmática aún no había sido publicada.

Don Manuel de la Torre y Castaños, "cabo principal y gobernador de la compañía de Lanzas de la guardia de Su Excelencia" (A.G.N., 1752, f. 7v.), padre legítimo de $D^{a}$ Ana de la Torre, se sentía deshonrado no por el hecho de que el supuesto violador de su hija fuese casado, sino porque había una enorme disparidad y desigualdad entre el reo, pobre y mulato, y su hija, española de pura cepa. Como decía el padre ultrajado, el reo no tuvo en consideración "la total disparidad de su persona pues siendo como es mulato y mi hija española por los cuatro costados" (A.G.N., 1752, f. 1v.), la injuria era enorme, porque, además, había que llevar en cuenta que su familia (del padre) era bien conocida y sus otras hijas estaban todas casadas con hombres honrados.

La cuestión del honor, como se sabe, era un punto basilar de la cohesión familiar, social, política y económica $y$, como advierte Bustamante, de alguna manera se fue estableciendo una identificación, binaria y simplista, entre "honor, posición, prestigio y las características fenotípicas. Ser noble, blanco, tener un origen conocido, prestigioso y legítimo significaba tener honor; mientras que, al contrario, ser negro, esclavo o descendiente de negro, ilegítimo, significaba infamia y deshonra" (Bustamante, 2019, p. 103).

Y ese era el único y principal argumento presentado para solicitar la prisión de Francisco de las Llagas, que tenía 36 años y estaba casado y tenía seis hijos, lo cual solo agravaría aún más sus crímenes. El mandato de prisión fue expedido inmediatamente al final de la fase sumaria. Como se puede ver, en ese momento inicial del proceso, la presunción de que no se podía tolerar un casamiento desigual fue el fundamento de la acusación, cuando aún la Pragmática no había sido publicada.

A continuación, ya en la fase probatoria, los argumentos, tanto de la acusación cuanto de la defensa, dejaron aún más explícitas las presunciones y suposiciones asumidas como reconocidas por todos.

\footnotetext{
${ }^{19}$ En la hoja inicial del proceso, escrito con la letra del organizador del archivo, se puede leer "pardo libre". En la hoja 1v, cabeza del proceso, el autor del inquirido, D. Manuel de la Torre y Castanho, lo define como "mulato". De cualquier manera, ambos términos indican la disparidad racial y social.
} 
Así, D. Manuel de la Torre afirmaba "no ser presumible que una niña doncella y recatada pasase a solicitar al dicho Francisco" (A.G.N., 1752, f. 7v.). Y no se podría presumir una cosa como esa porque, de acuerdo con la opinión de la acusación, aunque la niña estuviera ciega por la pasión, no podía "dejar de conocer la total disparidad de su persona y del dicho mulato" (A.G.N., 1752, f. 7v.).

Como se puede ver, de la Torre volvía a presentar, de forma más orgánica y argumentada, los mismos fundamentos de la sumaria. Se presumía (se daba por supuesto) que la desigualdad social y étnica era, per se, suficiente para probar el dolo del reo. Se trataba, sin duda, de una presunción que debería estar fuertemente asentada en la sociedad, sin embargo, como también se puede ver, la propia sociedad ya estaba cambiando no solo con relación a esa forma de pensar, sino principalmente en su manera de actuar. Si no fuese así, los desórdenes a que se refería la Pragmática Sanción, 26 años después, no tendrían sentido.

Vemos surgir aquí, como argumento, precisamente aquello que la Pragmática Sanción, un cuarto de siglo después, considerará como elemento extremamente peligroso y profundamente desestabilizador del orden social: el amor, la pasión ciega. Como se sabe, la palabra "pasión" servía como atenuante de algunos crímenes, ya que se consideraba que sentimientos arrebatadores turbaban la percepción de la realidad y llevaban a las personas al descontrol y a la falta de templanza.

Pero era precisamente eso lo que la Pragmática estaba intentando cambiar: en vez de considerar la "ciega pasión" como un atenuante, después de 1778 -y no a esas alturas, por lo tanto, porque aún no había sido promulgada - la pasión sería la malvada de la historia.

Con la Pragmática se pretendía legalmente evitar que el motivo de las uniones conyugales fuese precisamente la pasión amorosa. Y esa sería una de las funciones principales de la "patria potestad", que reforzaba su carácter de guardián de la honra femenina.

Como indicaba Bustamante, "a fines del siglo XVIII se alude, en cambio, a la voluntad entendida como deseo, pero no solo en el sentido tradicional de albedrío, sino como expresión de amor a la pareja, expresión que subrayaba el individualismo: el amor como razón explicitada para querer casarse" (Bustamante, 1995, p. 137). Y, en ese sentido, concluía que el amor nacido de la pasión se fue configurando, entonces, en un motivo importante para elegir la pareja de tal forma que los jóvenes estaban dispuestos a renunciar al apellido, al patrimonio familiar y al honor, para hacer valer el afecto y el deseo a la hora de casarse.

Era ese tipo de amor el que debía ser controlado por la patria potestad, de acuerdo con la Pragmática Sanción. Pero, como veremos, lo que realmente llama la atención en todo este proceso es que 26 años antes de su publicación quien recurrió a la categoría de "patria potestad" no fue la acusación, sino la defensa, utilizándolo para defenderse de la acusación de estupro y para contraatacar a la otra parte, acusando al padre de la víctima de no haber ejercido convenientemente las funciones y obligaciones emergentes de dicho poder. La defensa de Francisco de las Llagas organizó ordenadamente sus argumentos.

En primer lugar, negó la acusación de estupro $y$, negándola, puso todo el peso del debate en la contraargumentación, afirmando que D. Manuel no había cumplido sus deberes emergentes de cabeza de familia. Esa estrategia trastocó de tal forma todo el proceso probatorio que, en mi opinión, cambiaron los papeles.

El acusado negaba el estupro afirmando que no había ni pruebas ni testigos - cosa que, por otra parte, era común en ese tipo de delitos - y que, si algo debía ser presumido, teniendo en cuenta las circunstancias y condiciones en que los actos de ambos se desarrollaron, sería, por un lado, la voluntariedad y el deseo por parte de $D^{a}$ Ana y, por otro, la negligencia en el cumplimiento de sus deberes por parte de D. Manuel. Como la defensa explicaba, no se trataba de una niña doncella, sino de una mujer de 20 años, consciente de lo que hacía y quería, porque tenía "maduro juicio y talento" (A.G.N., 1752, f. 22r) y sabía que no habría ninguna posibilidad ni promesa de casamiento porque ella conocía que era un hombre casado, cargado de hijos y pobre. 


\section{Rafael Ruiz}

Para que se pudiera admitir que había existido el estupro, continuaba la defensa, era preciso probar que habían concurrido concomitantemente las circunstancias referidas por los autores y doctores más escrupulosos y rigoristas ${ }^{20}$, lo que no se verificaba, porque Francisco entró "a las 4 de la mañana por el corral (...) y se salió voluntariamente sin precisión de coacción alguna induciendola por sus mismos pasos voluntariamente a un rancho que ya se le tenia prevenido y destinado en La Venturosa" (A.G.N., 1752, f. 22r). Por lo tanto, lo que se debía presumir era que $D^{a}$ Ana "estaba tan determinada a salir de la casa de su padre, que fue fácil sacarla porque ya estaba prevenida" (A.G.N., 1752, f. 13v).

Como dije, este argumento era común en crímenes de este tipo. El supuesto estuprador, si quería verse libre de la condenación y de la pena, tenía que probar el consentimiento y voluntariedad de la mujer. Como también en este caso normalmente no había testigos, se entraba entonces en el terreno de lo verosímil, a partir de otros indicios, como las circunstancias en que los hechos sucedieron.

Lo que me interesa en este artículo es mostrar como una "presunción" argumentativa se contesta conotrapresunción. Y me interesa ver cómo una serie de presunciones pueden configurar una prueba suficiente para la convicción del juez, como, de hecho, sucedió en este caso.

De hecho, en ningún momento, ni en las alegaciones, ni en las réplicas, D. Manuel de la Torre insistió en la acusación de estupro y adulterio, concentrándose tan solo en aquel contraataque que el reo presentó, impugnando su falta de celo en el cumplimiento del deber de guardar el honor de su hija como buen padre de familia.

O sea, en mitad del proceso, en la fase probatoria, no se presentó ninguna prueba que confirmase ni el estupro ni el adulterio y todo quedó girando alrededor de la "patria potestad", invocada paradójicamente por la defensa, no por la acusación, de tal manera que de una múltiple y compleja acusación que abarcaba cuatro delitos (rapto, estupro, adulterio e invasión de morada) se pasó a un debate probatorio sobre el ejercicio adecuado o no de la "patria potestad", donde quien era acusado invirtió su rol en el proceso y se defendió acusando.

En ese sentido, la defensa presentó una narrativa explicando cómo Francisco era frecuentador asiduo de la casa de D. Manuel, cómo eran buenos amigos y cómo habían llegado a comer juntos, incluso contando con la presencia de $D^{a}$ Ana. Por lo tanto, continuaba la defensa, lo que se debería presumirera que, a pesar de la desigualdad, lo que había era familiaridad y, por lo tanto, lo que "se debe imaginar" (A.G.N., 1752, f. 12v.) era que la desigualdad, las diferencias de castas y económicas no tenían tanto peso, porque lo que había era una comunicación y amistad entre las partes (A.G.N., 1752, f. 12v.). De tal forma, continuaba la defensa, que $D^{a}$ Ana ganó confianza y libertad con Francisco hasta el punto de pedirle que "la libertase de la inhumanidad de su padre" (A.G.N., 1752, f. 12v), y el reo condescendió con el pedido, porque veía el rigor con que su padre la maltrataba.

¿Qué era lo que se estaba discutiendo en este proceso? Me parece que la cuestión central de toda la fase probatoria estuvo concentrada en la discusión sobre el ejercicio de la patria potestad y de cómo ese poder era entendido por la mayor parte de la población. De no ser así, las presunciones presentadas no tendrían fuerza de prueba.

La defensa estaba construyendo una narrativa ficcional ${ }^{21}$ y argumentativa que le permitiría probar, por presunción, que, si las cosas eran así, era porque así lo había querido el propio D. Manuel y, una vez asentado el supuesto, se tornaba verosímil la acusación de que era el padre quien había descuidado ejercer su "patria potestad".

\footnotetext{
${ }^{20}$ Dentro del probabilismo, los términos "escrupulosos" y "rigoristas" hacían referencia a aquellos que seguían la opinión más segura (eran también llamados tucioristas).

${ }^{21}$ Utilizo el término "ficción" en su sentido original y etimológico, del latín fingo-ere, con varios significados como "formar, dar forma, modelar, imaginar, suponer, inventar" y, también, "fingir", pero me interesan los significados citados en primer lugar (seis diferentes de "fingir"). En ese sentido, un argumento retórico es ficcional, no porque sea falso o mentiroso o porque se oponga a la realidad, sino porque tiene que ver con la mejor forma de encontrar un argumento, una manera de decir que pueda convencer al juez. No se puede olvidar que una de las partes de la Retórica es la inventio (no en el sentido, de nuevo, de inventar, sino en el etimológico de "encontrar").
} 
¿Cómo fue presentada la prueba? Una vez establecida la familiaridad y la convivencia continua en la casa de D. Manuel, la defensa recordó a los Oidores Reales la obligación de los padres de defender y cuidar la pureza y virginidad de sus hijas y el honor de la familia, protegiéndolas, incluso en el ámbito doméstico, del trato con otros hombres que no fueran parientes próximos y familiares: "Ios padres de familia deben siempre premeditar [...] el quitar las ocasiones que franquea qualquiera leve comunicación o familiaridad de qualquier hombre" (A.G.N., 1752, f. 13v).

$\mathrm{Si}$, por un lado, la "patria potestad", en lo que se relacionaba con la imposición de la voluntad paterna en el casamiento de los hijos, estaba perdiendo fuerza y vigencia social, por otro lado, la tutela y el celo del honor familiar y el de las hijas doncellas aún se mantenían como una fuerte costumbre social. Era un presupuesto originario que, como afirmaba la defensa de las Llagas, los padres debían gobernar a los hijos, y más si eran hijas, "con discreción para evitar irreparables prejuicios" (A.G.N., 1752, f. 13v.).

Como se sabe, la idea de "sexo débil" conjugada con las obligaciones impuestas por la noción del honor, imponían al cabeza de familia el deber de "resguardar el honor familiar mediante la prédica del recogimiento que garantizaba la virtud femenina" (Bustamante, 2019, p. 106). Esa era la creencia y opinión común compartida por una sociedad transida de cultura católica y régimen patriarcal. Era deber del padre de familia celar por el recato y resguardo de sus hijas en casa no solo con relación al trato directo o indirecto, sino aún de la mirada ajena de los hombres. Y fue precisamente en esa presunción, aceptada por todos o por lo menos por la gran mayoría, que la defensa se apoyó. Sin embargo, por otro lado, como se puede deducir del hecho de que se hiciera necesario publicar y aplicar la Pragmática Sanción, esa misma patria potestad encontraba sus brechas y sus puntos de fractura en esa misma sociedad, en aquello que hacía referencia a la interferencia paterna en la elección de los cónyuges.

Y para completar y reforzar ese contraargumento, la defensa acusaba a D. Manuel de ser inhumano, no solo por tratar con dureza y aspereza a su hija, como ella misma había contado varias veces al reo, sino por haber procesado a Francisco de las Llagas por crimen de rapto y estupro, siendo que, no solo no los hubo, sino que, siendo la naturaleza de esos crímenes de orden privado, no debería haber expuesto, como lo hizo, públicamente a su hija. Lo acusaba, por lo tanto, de "descuido, omisión y negligencia (...) y haber procedido con su hija con excesiva inhumanidad" (A.G.N., 1752, f. 13v).

Por último, apelaba a la misericordia del Tribunal, porque, además de pobre de la cabeza a los pies, era padre de seis hijos, uno de ellos enfermo, y tenía una mujer ya mayor y también enferma, a quienes tenía que cuidar y, por eso, la defensa recordaba que existía también un principio común y asentado en la doctrina de que no debería ser condenado porque si les faltase a ellos, acabarían por padecer hambre y miseria (A.G.N., 1752, f. 16v).

La sentencia fue dada el 1. de junio de 1753 y fue relativamente leve: seis meses de destierro. La acusación contestó la sentencia con nuevas alegaciones, exigiendo una pena con un plazo bien mayor, pero la Real Audiencia mantuvo el plazo de los seis meses, a contar de cuando fue dada la sentencia, lo que, a final de cuentas, redujo la pena para cuatro meses. Las presunciones de la defensa de Francisco de las Llagas persuadieron a los oidores de la Audiencia de Lima.

El segundo caso empieza con un auto de la Real Audiencia para resolver el pedido de impedimento de matrimonio, interpuesto con base en la Pragmática Sanción y, simultáneamente, con la acusación de rapto y estupro (A.G.N., 1800, L. 91, C. 1127).

Don Pablo Núñez y Ansures rehusaba dar su consentimiento para que su hija Manuela, de 17 años, se casase con Severino de los Santos, mulato y pobre. El Tribunal citó las partes en el plazo de ocho días para que presentasen sus argumentos y pudiese emitir su sentencia sobre la racionalidad o irracionalidad de la medida paterna (A.G.N.,1800, f. 9r). Como se sabe, en los juicios de disenso se discutía si había o no una justa y racional causa para no dar el consentimiento paterno. 
El autor del proceso, de familia española, reivindicaba queel casamiento desuhijaManuelaconelmulatoSeverino fuese impedido, teniendo en cuenta la desigualdad entre las partes y las familias. Los argumentos que D. Pablo presentó se apoyaban en la cultura patriarcal de la época y en el texto de la Pragmática Sanción: una vez más, la disparidad y la desigualdad entre las partes.

En primer lugar, acusaba a Severino de ser "un sujeto de lo más bajo y despreciable de la plebe de Supe" (A.G.N., 1800, f. 22r), un pueblo en la región de la costa al norte del Perú, entre Lima y Trujillo. La utilización de la categoría "plebe" era intencional y despectiva. Se trataba de un término con el cual la élite manifestaba su desprecio e incluso recelo con relación a "esa mezcla abigarrada de mestizos y gente de castas, pero también de indios urbanos y españoles pobres, muchos de ellos carentes de trabajo formal y estable; una multitud con una base económica precaria, identificada por las élites como gente vil, vagabunda, carente de honor, disoluta, ignorante y cercana a la criminalidad" (Bustamante, 2019, p. 121).

A seguir, atacaba su condición de "mestizo de chino"22 y nieto de india tributaria para concluir que la condición de Severino no podía ser ni más baja ni más corrupta (A.G.N., 1800, f. 22r) y que sería totalmente imposible que se pudiese realizar la unión entre las dos familias, precisamente por las determinaciones de la Real Pragmática Sanción de Carlos III, orientada principalmente contra "todas las castas de negros, mestizos, coyotes ${ }^{23}$ y demás individuos raros" (A.G.N., 1800 , f. 23r).

Finalmente, insistía en que el problema, como trataba de resolverlo la Ley Regia, no era tan solo la "desigualdad", sino también "la corrupción de costumbres y escandalosos ejemplos de la família de Severino", de los cuales no quería hablar por caridad cristiana, pero dejaba caer que la abuela de Severino había sido una prostituta (A.G.N., 1800, f. 23r). Con todo eso, concluía la alegación de la acusación, ¿podría "darse generación más baja ni origen más corrompido para enlazarla con una familia de honor y distinción como lo es la de $D$. Pablo y D. Manuela?" (A.G.N., 1800, f. 22v).

Era por esos motivos que Don Pablo Núñez y Ansures solicitaba de la Justicia que declarase "justo y racional su discurso para que de ninguna suerte pueda ni deba llevarse a debido efecto" y que condenase a Severino por el crimen de estupro (A.G.N., 1800, f. 22r).

A su vez, y en su defensa, Severino de los Santos declaró (A.G.N., 1800, f. 24v) que era consciente de que el padre de Manuela se oponía al casamiento porque consideraba que era un matrimonio desigual, sin embargo, quería aclarar que su abuela había sido una india noble, "hija de un cacique" (A.G.N., 1800, f. 6r) y era india libre y no tributaria y que su padre era, de hecho, mestizo y jornalero (A.G.N., 1800, f. 6r), pero que, por un lado, también podían ser encontrados mestizos en la familia de D. Pablo porque, en primer lugar, una sobrina era también mestiza, y su suegra también lo era y, más aún, se había casado con un "chino" conocido en todo el pueblo con el nombre de Napuri (A.G.N. Real Audiencia. Causas Criminales. L 91, C 1127, Año 1800, f. 39r). Y aun había otra sobrina, María Clara de nombre, que llevaba casada más de un año con otro "chino nombrado Pablo que ejerce el oficio de platero em Guacho" (A.G.N., 1800, f. 39r).

Por otro lado, en lo que hacía referencia a la sangre, raza y oficio, Severino argumentaba que el hecho de ser mestizo no significaba que fuese ni de baja condición, ni débil ni desreglado, sino que, al contrario, "vemos que muchos han obtenido empleos honoríficos en las carreras civil y eclesiastica y que Su Majestad no los excluye de ejercerlas" (A.G.N., 1800, f. 37v). Y, continuaba la defensa,

\footnotetext{
${ }^{22}$ El término chino se atribuía al mestizo de mulato con indígena. La expresión en femenino, china, originariamente era un término quechua para designar "mujer" y tenía un sentido más lato, pudiendo ser usado en relaciones afectivas y, de esa forma, podía ser dirigido a cualquier mujer próxima, aunque no fuera india. Para todo esto y otros términos y sentido de connotación étnica, ver Durand (1964).

${ }^{23}$ El término coyote se usaba para designar a los descendientes de mestizo (de español con indígena) con indígenas.
} 
por fuerza de la Real Cédula de 18 de marzo de $1783^{24}$, no se podía decir que hubiese ningún oficio bajo, deshonesto o deshonrado, aunque fueran los oficios de herrero, sastre, zapatero o curtidor, porque ni ellos ni las personas de sus familias quedaban inhabilitados para ejercer los empleos municipales de la República (A.G.N., 1800, f. 37v).

Hasta aquí, la argumentación de la defensa siguió con rigor la lógica argumentativa de la retórica y dialéctica aristotélica. Ante los hechos descalificadores presentados por Don Pablo, la defensa expuso que esos mismos hechos también podían ser encontrados en la familia del padre de Manuela. Y ante el argumento de desigualdad social y económica que la Pragmática Sanción prohibía, Severino presentaba otra Real Cédula que defendía el honor y la honestidad de las profesiones manuales como, por otra parte, correspondía a los planes de reforma puestos en práctica por los Borbones-, y añadía que ninguna persona que perteneciera a esos oficios ni sus familiares estaban prohibidos o impedidos de ejercerlos. Se trataba, por lo tanto, de una cuestión de estrategia retórica: contra una ley regia preocupada por los desórdenes provocados por los casamientos desiguales, otra ley regia preocupada por la movilidad social a partir del ejercicio de profesiones manuales. Hechos contra hechos. Leyes contra leyes.

Por último, y aquí me parece que reside la fuerza de sus argumentos, Severino presentaba la cuestión moral y religiosa, dentro de la categoría de la "patria potestad", y justamente ante el juicio civil. Antes de presentar su argumento decisivo, explicaba los hechos: ya vivían hacía dos años juntos como marido y mujer, aunque no se habían casado y, para Don Pablo, hasta la fecha era como si no existieran. No se podía presumir, por lo tanto, que hubiera ocurrido un estupro continuado, sino la voluntariedad y la libre elección de la vida marital por parte de Manuela. Y tampoco era verosímil que solamente después de dos años, D. Pablo se diese cuenta y se preocupase por la desigualdad entre las familias.
Severino colocaba en el centro de su argumentación, al igual que Francisco de las Llagas en el otro proceso, el argumento amoroso como fundamento de un nuevo tipo de presunción. Como afirmaba Bustamante, el "amor" iba transformándose en un elemento o factor subversivo, provocando que "la gente descuidara las jerarquías de calidad, de sexo y de generación" (Bustamante, 2019, p. 139) y, en ese sentido, la Pragmática Sanción, bien como la invocación de esta por parte de D. Pablo, "era un intento por reposicionar el concepto corporativo de la unidad familiar barroca, en decadencia, e impedir una independencia mayor en la selección de la pareja conyugal para reforzar el patriarcado" (Bustamante, 2019, p. 139).

Sin embargo, continuaba Severino intentando reforzar más aún que no había habido ninguna violencia de su parte, cuando en la ciudad apareció el misionero Francisco José Gómez, Manuela pasó a tener serias crisis de conciencia "por las confesiones y comuniones sacrílegas que según ella misma dijo había tenido anteriormente" (A.G.N., 1800, f. 23v) e insistió, entonces, en querer casarse. Y fue tan solo en ese momento, después de que habían buscado al Padre Iturri para que oficiara la ceremonia, que Don Pablo entró en la Justicia con dos procesos simultáneos: uno para impedir el casamiento y el otro para acusarlo de estupro.

Después de exponer su narrativa sobre los hechos, la defensa organizó sus argumentos partiendo de presunciones sobre la figura del buen padre de familia, que eran reconocidas como vigentes y válidas por todos dentro de aquella cultura católica. Lo que, de nuevo, llama la atención es que, tal como en el anterior proceso, la "patria potestad" sea invocada por la defensa y no por la acusación.

Decía Severino que cuando ambos estaban decididos a "ponernos en gracia de Dios y en autorizar y hacer indisoluble nuestro enlace con las bendiciones de la

\footnotetext{
${ }^{24}$ El mismo encabezamiento de la ley ya era suficientemente significativo: Real Cédula de S. M. y señores del Consejo, por la qual se declara que no sólo el oficio de curtidor, sino también los demás artes y ofícios de herrero, sastre, zapatero, carpinteiro y otros... son honestos y honrados; y que el uso de ellos no envilece ni inhabilita para obtener los empleos municipales de la República en que estén avecinados... Biblioteca Digital Hispánica (Biblioteca Nacional). Recuperado de: http://bdh.bne.es/bnesearch/biblioteca [fecha de consulta: 6 de mayo de 2020].
} 


\section{Rafael Ruiz}

iglesia" (A.G.N., 1800, f. 37r), precisamente en esa hora, apareció Don Pablo diciendo que "no soy igual a su hija en nacimiento, me trata de raptor y solicita prisiones y castigos contra mî" (A.G.N., 1800, f. 37v).

La imagen presumida que fue construida por Severino fue la de un buen padre de familia católica, de la cual distaba mucho Don Pablo y era por eso que insistía en mostrar la contradicción entre lo que Don Pablo estaba reivindicando (el impedimento del casamiento) y lo que debería ser el comportamiento adecuado y correcto de alguien que ejerciera la "patria potestad": "Que conducta tan opuesta a las máximas de nuestra sagrada religión! Que procedimiento tan irregular y tan extraño el consentir D. Pablo que su hija se mantenga en un comercio ilícito y no convenir en que se santifique mi unión con ella" (A.G.N., 1800, f. 37v).

Y, luego, continuaba argumentando sobre lo que verdaderamente Don Pablo estaba pensando: "Viva sin honor (viene él a decir) fuera del matrimonio, aunque ofenda en esto a Dios, escandalice al pueblo y ponga su alma en riesgo de perderse y no viva honrada con aquel sagrado vínculo en gracia de Dios y edificación del próximo. Que horrible modo de pensar!" (A.G.N., 1800, f. 37v).

Son dos ficciones narrativas sobre el padre de Manuela, una con relación a la conducta inadecuada frente a los mandamientos de la ley de Dios y otra con relación a lo que debía estar pensando. Ambas se apoyaban en presunciones, el reo hacía como si supiera lo que verdaderamente Don Pablo estaba pensando. No habría posibilidad de saberse con certeza si era eso o no lo que pensaba Don Pablo, pero eran presunciones, narrativas y argumentos verosímiles cuya fuerza consistía en su verosimilitud, en su proximidad con lo que solía suceder, con lo que en general todos pensaban y aceptaban como normal. Todo ese conjunto de narrativas, argumentos y presunciones daban consistencia y fuerza probatoria a la defensa y hacía inclinarse la convicción de los jueces en su favor.
Las dos presunciones de la defensa se apoyaban en aquello que se esperaba del ejercicio de la "patria potestad", sin embargo, de la misma forma que en el proceso de 1752, se admitía un tipo de ejercicio de ese mismo poder - celar por el estado de gracia de los miembros de la familia, principalmente de las hijas-, pero ya no se aceptaba más que ese mismo poder coartase el libre albedrío y el amor de los novios.

El Tribunal de la Real Audiencia de Lima, en contra de lo que se esperaría teniendo en cuenta lo que normalmente se entiende por "patriarcado en el Antiguo Régimen", declaró "irracional" el pedido presentado por Don Pablo y concedió permiso para el matrimonio de Severino y Manuela.

Autos y vistos porlo que resulta de este proceso sumario extrajudicial e informativo se declara por irracional el discurso de D. Pablo Núñez y Ansures para que pueda contraer matrimonio su hija D. Manuela Núñez con Severino de los Santos, en cuya consecuencia, supliendole como desde luego se le suple por la autoridad de este Juzgado a la enunciada D. Manuela el debido y correspondiente consentimiento para que pueda celebrar y contraer el dicho matrimonio se le habilita al efecto (A.G.N., 1800, f. 39v).

Con otras palabras, incluso contra la disposición expresa de la Pragmática Sanción, los Oidores reales se declaraban a favor del amor de los novios y en contra de los criterios segregacionistas y elitistas de la ley de Carlos III, reinterpretando la categoría de "patria potestad". 


\section{Consideraciones finales}

A lo largo de todo el artículo he querido destacar dos cuestiones que me parecen de interés cuando se estudia la administración de la justicia y la práctica procesal en la América española del siglo XVIII: el papel de la retórica como prueba y sus implicaciones con la teología moral, por un lado, y, por otro, los cambios de significado y de vigencia social que la categoría "patria potestad" fue sufriendo en un espectro de 50 años, antes y después de la publicación de la Pragmática Sanción de Carlos III, en 1778.

He intentado mostrar cómo la retórica, en cuanto parte de la filosofía, se fue abriendo camino y adaptando al mundo jurídico y procesal, principalmente a partir del momento en que la idea de "verdad" fue siendo dejada de lado y poco a poco fue siendo substituida por la de "certeza moral", especialmente desde el desarrollo de lo que se fue entendiendo como prueba por indicios, por conjeturas, por argumentos y presunciones. Y, en este sentido, me he detenido a explicar cómo, desde el punto de vista moral (que estaba intrínsecamente ligado al jurídico) la Compañía de Jesús se hizo responsable de realizar una transformación de la moralidad católica, pasando del tuciorismo (seguir lo más seguro) medieval para un probabilismo ya plenamente moderno, subjetivo y flexible. Y he procurado explicar cómo esos ámbitos de lo retórico, lo moral y lo jurídico incidían en la conciencia del juez, que era la que debía ser persuadida y convencida, a partir de los argumentos presentados como pruebas de la verdad probable de los hechos.

A partir de ese punto, he analizado dos procesos similares, uno antes y otro después de la Pragmática Sanción, que pretendía reforzar la patria potestad de los cabezas de familia para evitar los continuos desórdenes que los matrimonios desiguales estaban provocando en el Virreinato del Perú. Y, a partir del análisis de las presunciones que cada parte presentó en su acusación o su defensa, he intentado hacer ver cómo se hace necesario no solo revisar algunas ideas consagradas y cristalizadas sobre categorías históricas del período conocido como Antiguo Régimen, sino que también se hace necesario plantear el estudio de los procesos a partir de sus propios medios de prueba y de su estructura argumentativa, ya que esos análisis pueden darnos una visión más amplia y más profunda no solo de las formas de decir el derecho, sino también de las formas de aplicarlo y hacerlo efectivo.

En concreto, espero haber mostrado cómo la categoría de "patria potestad" sufrió un proceso de erosión semántica a lo largo de la segunda mitad del siglo XVIII, de tal forma que si, por un lado, aún mantenían su vigencia social las ideas tradicionales de "sexo débil", "honor familiar" "recato femenino" o "virginidad", tan solo para citar aquellos valores que se podrían incluir dentro de la categoría de "celo y cuidado del padre de familia", por otro lado, y aún en contra de las disposiciones reales, ya no tiene fuerza de costumbre la práctica del consentimiento paterno previo al enlace conyugal. Como se puede ver por los procesos presentados, la idea de "libre albedrío" y de "voluntad individual", incluso con un marcado acento sentimental a partir del reconocimiento de la importancia del "amor" y de la "pasión amorosa", es reconocida por los tribunales, probablemente porque ya antes era reconocida por la sociedad limeña de finales del siglo XVIII. 


\section{Referencias}

\section{Fuentes manuscritas:}

Archivo General de la Nación de Lima (A.G.N.). Real Audiencia. Causas Criminales. L. 15, C 161, Año 1752. Causa seguida por D. Manuel de la Torre y Castaño contra Francisco de las Llagas pardo libre por el rapto de su hija doncella. Archivo General de la Nación de Lima (A.G.N.) Real Audiencia. Causas Criminales. L 91, C 1127, Año 1800. Causa seguida por D. Pablo Núñez y Ansures contra Severino de los Santos por estupro de Manuela Núñez su hija.

\section{Libros de referencia:}

Agüero, A. (2008). Castigar y perdonar cuando conviene a la República: La justicia penal de Córdoba del Tucumán. Siglos XVII y XVIII. Madrid: Centro de Estudios Políticos y Constitucionales.

Aquino, Tomás de (s.f.). Summa Theologiae. Recuperado de: https://www.documentacatholicaomnia. eu/03d/1225-1274,_Thomas_Aquinas,_Summa_Theologiae,_ES.pdf

Ares, B. (2015). Usos y abusos del concepto de casta en el Perú colonial. Ponencia inédita presentada en el Congreso Internacional INTERINDI 2015. Categorías e indigenismo en América Latina, EEHACSIC. Congreso llevado a cabo en Sevilla.

Aristóteles. (1999). Retórica (2ª reimpresión). (Trad. Quintín Racionero). Madrid: Biblioteca Clásica Gredos.

Barreneche, O. (1993). "Esos torpes deseos": Delitos y desviaciones sexuales en Buenos Aires, 1760-1810. Estudios de Historia colonial, (13), 29-45.

Belda Plans, J. (2000). La Escuela de Salamanca: La renovación de la Teología en el siglo XV. Madrid: BAC.

Bistué, N. del C. y Marigliano, C. (1992). Los disensos matrimoniales en la Mendoza virreinal (1778-1810). Revista de Historia del Derecho, (20), 75-101.

Bustamante O., L. (2019). Matrimonio y violencia doméstica en Lima Colonial (1795-1820). Lima: Universidad de Lima, Fondo Editorial.

Caro B., J. (1978). Las formas complejas de la vida religiosa: Religión, sociedad y carácter en la España de los siglos XVI y XVII. Madrid: Akal.

Chilló, J. M. (2015). Ser, conocimiento y lenguaje en De Interterpretatione, 16a 3: Rudimentos para una Teoría del significado en Aristóteles. Rivista di Filosofia Neo-Scolastica. 107 (3), 501-519.

Durand, J. (1964). Castas y clases en el habla de Lima. En Caravelle (3): Actes du colloque sur le problème des capitales en Amérique latine (pp. 99-108). Recuperado de: https://www.persee.fr/doc/carav_0184-7694_1964_ nun_3_1_1091 [fecha de consulta: 6 de mayo de 2020].

Fuentes-Barragán, A. (2015). Sobre estrategias y pasiones: Etnicidad, honor y matrimonio en la Provincia de Buenos Aires (siglo XVIII). Revista Dos Puntas, Año VII, (12), 115-135.

Fuentes-Barragán, A. (2016). Entre acuerdos y discordias: La Pragmática Sanción para evitar el abuso de contraer matrimonios desiguales en la provincia de Buenos Aires. Revista Historia y Memoria, (12), 53-84.

Ghirardi, M. (2004). Matrimonios y familias en Córdoba: Prácticas y representaciones. Córdoba: Universidad Nacional de Córdoba.

Ghirardi, M. (2007). Familias, poderes, instituciones y conflictos. Iglesia, preceptos y transgresiones. La vertiente americana. En F. Chacón, J. Hernández y F. García (Eds.). Familia y organización social en Europa y América, siglos XV-XX (pp. 109-130). Murcia: Ediciones de la Universidad de Murcia.

Ginzburg, C. (1989). Mitos, emblemas, sinais: morfología e história (Trad. Federico Carotti). São Paulo: Companhia 
das Letras.

Giraudo, L. (2018). Casta(s), "sociedad de castas" e indigenismo: La interpretación del pasado colonial en el siglo XIX. Nuevo Mundo Mundos Nuevos, Debates. Recuperado de: https://journals.openedition.org/nuevomundo/72080?lang=es [fecha de consulta: 20 de junio de 2020] doi: https://doi.org/10.4000/nuevomundo.72080

Giuliani, A. (1964). II concetto classico di prova: la prova come "argumentum". En Société Jean Bodin Pour l'Histoire Comparative Des Institutions (Ed.). La preuve. Antiquité, Vol. 1 (pp. 357-388). Bruxelles: Éditions de la Librairie Encyclopédique.

Gonzalbo, P. (2013). La trampa de las castas. En S. Alberro y P. Gonzalbo. La sociedad novohispana: Estereotipos y realidades (pp. 15-193). México: El Colegio de México.

Grossi, P. (Ed.). (1973). La Seconda Scolastica nella formazione del diritto privato moderno. Giuffré: Firenze.

Gutiérrez, R. (1993). Cuando Jesús llegó, las madres del maíz se fueron: matrimonio, sexualidade y poder em Nuevo México. México, D.F.: Fondo de Cultura Econômica.

Kluger, V. (1997). Los deberes y derechos paterno-filiales a través de los juicios de disenso: Virreinato del Río de la Plata (1785- 1812). Revista de Historia del Derecho, (25), 365-390.

Konetzke, R. (1962). Colección de documentos para la historia de la formación social de Hispanoamérica (14931810). Madrid: Consejo Superior de Investigaciones Científicas (CSIC).

Lavrin, A. (Coord). (1991). Sexualidad y matrimonio en la América hispánica: Siglos XVI-XVIII. México, D.F.: Grijalbo.

Llamosas, E. (2011). Probabilismo, Probabiliorismo y Rigorismo: La Teología moral en la enseñanza y en la práxis judicial de la Córdoba tardocolonial. Cuadernos del Instituto Antonio de Nebrija, 14(2), 281-294.

Macera, P. (1963). Probabilismo en el Perú durante el siglo XVIII. Lima: Nueva Crónica. Universidad Nacional Mayor de San Marcos.

Marre, D. (1997). La Aplicación de la Pragmática Sanción de Carlos III en la América Latina: una Revisión. Quaderns del'Institut Català d'Antropologia, Barcelona, (10), 217-249.

Martel, V.H. (2007). El lugar del Probabilismo en las ideas políticas del Perú, Solar, 3 (3), 11-22.

Maryks, R. A. (2008). Saint Cicero and the Jesuits: The Influence of the Liberal Arts on the Adoption of Moral

Probabilism. Hampshire, Burlington - Rome: Ashgate Publishing - Institutum Historicum Societatis lesu.

Mayer, L. (2015). Rutas de incertidumbre: Ideas alternativas sobre la génesis de la probabilidad, siglos XVI y XVII. México, D.F.: FCE.

Menochio, G. (1595) De pressuntionibus, conjecturis, signiis et indiciis Conentaria. Coliniae Agripinae, apud loannem Gymniccun, sub Monocerote.

Muñoz García, Á. (2003). Diego de Avendaño, 1594-1698: filosofía, moralidad, derecho y política en el Perú colonial. Lima: UNMSM, Fondo Editorial.

Ortego G., P. (2009). Condenar ou absolver entre os juízes de Castela e o ludex commune. En A. P. B. Homem et al. (coed). O Perfil do juiz na Tradição Ocidental (pp. 133-164). Coimbra: Almedina.

Ortego G., P. (2012) El arbitrio de los jueces inferiores: su alcance y limitaciones. En J. Sánchez-Arcilla B. El arbitrio judicial en el Antiguo Régimen (España e Indias, siglos XVI-XVIII). Madrid: Dykinson.

Ortego G., P. (2013). Sentencias criminales en Castilla: entre jueces y abogados. Clío \& Crimen. Revista del Centro de Historia del Crimen de Durango, (10), 359-372.

Padoa-Schioppa. A. (2001). Sulla coscienza del giudice nel diritto comune. In luris Vincula, Studi in onore di Mario Talamanca VI (pp. 119-162). Napoli: Jovene Editore.

Palumbo, M. (2013). Conscientia, Casus conscientiae. In Conscientia nella filosofia della prima modernità (pp. 203235). R. Palaia (Ed.). Firenza: Leo S. Olschki Editore.

Perelman, C. (1979). La Lógica jurídica y la Nueva Retórica. Madrid: Editorial Civitas.

Perelman, C. (1997). El Imperio retórico: Retórica y Argumentación (Trad. A. León Gómez Giraldo). Bogotá: Editorial Norma.

Porro, N. (1978). Los juicios de disenso en el Río de la Plata: Nuevos aportes sobre la aplicación de la Pragmática de 


\section{Rafael Ruiz}

Hijos de Familia. En Actas del V Congreso del Instituto Internacional de Historia del Derecho Indiano. QuitoGuayaquil.

Prodi, P. (2005). Una história da Justiça. São Paulo: Martins Fontes.

Real Cédula (18 de marzo de 1783). Biblioteca Digital Hispânica (Biblioteca Nacional). Recuperado de http://bdh.bne. es/bnesearch/biblioteca. [Fecha de consulta: 6 de mayo de 2020].

Reboul, O. (2004). Introdução à Retórica (Trad. I. Castilho Benedetti). São Paulo: Martins Fontes.

Rosoni, I. (1995). Quae singula non prosunt collecta iuvant: La teoria della prova indiziaria nell'età medievale e moderna. Milano: Giuffrè.

Ruiz, R. (2017 a) La Teología moral y el Probabilismo jurídico em la América española de la Temprana Modernidad. En

O. R. Moutin y S. Terraneo. III Jornadas de Estudio del Derecho canónico indiano (Actas). Junín: De las Tres Lagunas.

Ruiz, R. (2017 b). Pruebas (DCH) (Evidences (DCH)) (October 2, 2017). Max Planck Institute for European Legal History Research Paper Series No. 2019-09. http://dx.doi.org/10.2139/ssrn.3363668 [Fecha de consulta: 6 de mayo de 2020].

Schüssler, R. (2005). On the Anatomy of Probabilism. En J. Kraye \& R. Saarinen, (Eds.). Moral Philosophy on the Threshold of Modernity, 57 (pp. 91-113). Dordrecht, Netherlands: Springer.

Seed, P. (1991). Amar, honrar y obedecer em el México colonial: Conflictos em torno a la elección matrimonial, 15741821. México, D.F.: Alianza Editorial.

Socolow, S. M. (1991). Cónyuges aceptables: la elección del consorte em la Argentina colonial, 1778-1819 (pp. 229270). En A. Lavrin (Coord.). Sexualidad y matrimonio en la América hispánica: Siglos XVI-XVIII, México. D.F.: Grijalbo.

Stolcke, V. (2009). Los mestizos no nacen, sino que se hacen. Avá: Revista de Antropología, (14). Recuperado de: https://www.redalyc.org/articulo.oa?id=1690/169013838002 [Fecha de consulta: 6 de mayo de 2020].

Taruffo, M. (2014). A prova (Trad. J. G. Couto). São Paulo: Marcial Pons.

Taruffo, M. (2005). La prueba de los hechos. Madrid: Trotta.

Todescan, F. (1973) Lex, natura, beatitudo: Il problema della legge nella scolastica spagnola del secolo XVI. Padova: Cedam.

Turrini, M. (1994). II giudice della coscienza e la coscienza del giudice. En P. Prodi (Ed.). Disciplina dell'anima, disciplina del corpo e disciplina della società tra medioevo ed età moderna (pp. 279-294). Bologna: II Mulino.

Turrini, M. (1996). Tra diritto e teologia in età moderna: spunti di indagine. In P. Prodi e W. Reinhard (Ed.). I/ Concilio de Trento e il moderno (pp. 225-269). Bologna: II Mulino.

Tutino, S. (2014). Shadows of Doubts: Language and Truth in Post-Reformation Catholic Culture. New York: Oxford University Press.

Tutino, S. (2018). Uncertainty in Post-Reformation Catholicism: A History of Probabilism. New York: Oxford University Press.

Twinam, A. (2007). Estado de la cuestión. La historia de la familia, la historia del género: pasado, presente y futuro. En F. Chacón, J. Hernández y F. García (Eds.). Familia y organización social en Europa y América, siglos XV-XX (pp. 329-342). Murcia: Universidad de Murcia.

Vidal García, M. (1986). Frente al rigorismo moral, Benignidad pastoral, Alfonso de Liguori (1696-1787). Madrid: Instituto Superior de Ciencias Morales, Perpetuo Socorro Editorial.

Villey, M. (1979). Compendio de Filosofía del Derecho, 2. Pamplona: Eunsa.

Vitellio, A. (2007). La certeza morale nel diritto canonico (Tesi di dotoratto). Università degli Studi di Napoli, Federico II. 